\title{
Psychological Impact of COVID-19 Pandemic on Pregnant Women
}

\author{
Rashida Sultana ${ }^{1}$, Anees Fatima ${ }^{2}$
}

${ }^{1}$ Associate Professor, Department of Obstetrics and Gynecology, Sharif Medical and Dental College, Lahore ${ }^{2}$ Senior Registrar, Department of Obstetrics and Gynecology, Sharif Medical and Dental College, Lahore

\section{ABSTRACT}

Background: Covid-19 pandemic has spread throughout the world in a short period of time. It has adversely affected the physical, mental and social well-being of communities including pregnant women. This study is aimed to determine the frequency, severity and associated factors of depression, anxiety and stress among pregnant women during COVID19 pandemic.

Material and Methods: This cross-sectional study was conducted in Sharif Medical City Hospital, Lahore, from August to September 2020.Data was obtained on structured proforma comprised of two sections. Section one consisted of sociodemographic and obstetric components while second two was based on Urdu Version of DASS-21. Data was analyzed using SPSS-23.

Results: Total number of women was 350 . Their mean age was $27.47 \pm 4.72$ while mean duration of their pregnancy was $26.33 \pm 9.17$ weeks. Mean DASS-21 score of depression, anxiety, and stress was $8.00 \pm 2.89,5.80 \pm 3.10$ and $9.18 \pm 2.80$ respectively. It was observed that depression was present in $123(35.1 \%)$ ranging from mild to moderate, anxiety in $127(36.3 \%)$ ranging from mild to very severe and stress in only $20(5.7 \%)$ women and was mild.

Education was significantly associated with all three domains. The women who were infected themselves or any other family member affected with COVID-19 showed positive association for depression $(p=0.00)$ and stress $(p=0.00)$. Stress was higher in young age groups $(p=0.04)$ and in women with higher monthly income $(p=0.00)$ while parity also showed association with anxiety $(p=001)$. Anxiety and depression were more in house wives $(p=0.00)$ while stress in working women $(p=0.00)$.

Conclusion: Frequency of depression and anxiety was notable varying from mild to very severe however for stress it was low and mild. Educational level was significantly associated with depression, anxiety, and stress.

Keywords: COVID-19, Pandemic, Psychological impact, Pregnancy, Postnatal

\begin{tabular}{|c|c|c|}
\hline Authors' Contribution: & Correspondence: & Article info: \\
\hline${ }^{1-2}$ Conception; Literature research; & Rashida Sultana & Received: December 29, \\
\hline $\begin{array}{l}\text { manuscript design and drafting; Critical } \\
\text { analysis and manuscript review; Data } \\
\text { analysis; Manuscript Editing. }\end{array}$ & Email:drrashidasultana@gmail.com & Accepted: September 8, \\
\hline
\end{tabular}

\section{Introduction}

The first case of COVID-19 was confirmed in Pakistan on $26^{\text {th }}$ February 2020 in Karachi. ${ }^{1}$ Number of cases have been increasing day by day throughout the world and the second phase of this pandemic is more severe than the initial phase with higher infectivity and mortality. ${ }^{2}$ This pandemic has caused severe social disruption, global recession and great uncertainty throughout the world. ${ }^{3}$ COVID-19 pandemic has not only disturbed daily life pregnant women but also affected their routine antenatal visits in developed world as well as in developing countries like Pakistan. Stress and anxiety during pregnancy is associated with preterm labor, premature births and increased risk of cesarean section. Moreover, women who have stress and anxiety during pregnancy have more chances of 
postpartum depression and problems related to breastfeeding. In long run, babies born to such mothers have more behavioral problems as compared to babies born to normal mothers. ${ }^{4}$ Timely psychological interventions during the antenatal period may result in better feto-maternal outcome so mothers must be inquired regarding underlying risk factors during antenatal visits to identify and treat the cause.

Objective of this study was to determine the frequency and severity of depression, anxiety, and stress and its associated factors among pregnant women during COVID-19 pandemic. Literature review of studies conducted in different localities of Pakistan over ten years revealed that prevalence of anxiety and depression ranges from $22 \%$ to $60 \%$ in Pakistani population. ${ }^{5}$ However, prevalence of depression among Pakistani women is reported high; ranging from $30 \%-65 \% .{ }^{6}$ When a woman gets pregnant, her role is changed to a mother and she becomes more vulnerable to physical as well as mental changes during pregnancy and in postpartum period under the effect of hormones. COVID-19 pandemic has detrimental effects on physical and mental health of people. Pregnant and postnatal women are at increased risk of developing depression and anxiety during COVID-19 pandemic. ${ }^{7,8}$ As anxiety, stress and depression during pregnancy have adverse feto-maternal implications so it is crucial to identify the psychological impact of COVID-19 pandemic particularly on pregnant women in terms of frequency and severity of depression, anxiety and stress.

\section{Material and Methods}

This descriptive study was conducted after ethical approval from Institutional Review committee; letter no. SMDC/SMRC/66-20. Place of study was Sharif Medical City Hospital, Lahore, Pakistan from August to September 2020. All pregnant women with singleton pregnancy at any gestational age presenting in the outpatient department for antenatal visit were included in the study after their consent.

Women with past or current history of psychiatric disorders, postpartum depression or on antipsychotic medication, high risk patients such as patients with cardiac disease, moderate to severe anemia, uncontrolled diabetes and hypertension and bad obstetric history were excluded to minimize confounding and to ensure that it is not related to pre-existing illness or complicated pregnancy. A sample size of 350 patients was calculated. Assumed proportion was taken as 0.65 , acceptable difference of 0.05 and confidence level of $95 \% .{ }^{9}$ Non probability convenience sampling technique was used. Data was collected on a structured questionnaire that had two sections. Sociodemographic characteristics of the study participants were enquired in Urdu language like age, parity, gestational age, personal or family history of COVID-19 disease, education, occupation and monthly income. It was followed by twenty-one questions of DASS-21 Urdu version. Study participants were explained that they must read the questionnaire carefully and encircle the response that applies most to them during last one week.

Depression, anxiety and stress scale is a 42 -item scale (DASS-42) with a shorter version comprised of 21 items known as DASS-21 and is divided into three subscales. There were seven questions per subscale. It measures the negative emotional states of depression, anxiety and stress. ${ }^{10}$ In this study, "Urdu Version" of DASS-21 was used. ${ }^{11}$ Each question is scored using Likert scale i.e., never $=0$, sometimes $=1$, often=2 and always=3. Depression, anxiety and stress level of women was determined according to pre-defined cut-off scores such that Depression $\geq 10$, anxiety $\geq 8$, and stress $\geq 15$ which are further categorized into mild, moderate, severe and very severe for each subscale. ${ }^{10}$

Data was entered and analyzed in SPSS 23. Mean and standard deviation was calculated for quantitative variables e.g., age, number of 
pregnancies, gestational age and monthly income. Qualitative variables like age groups, educational status, occupation and COVID status was calculated in percentages. Scores obtained by the Likert scales were categorized according to predefined cut-off values of DASS-21 and were calculated in percentages. Independent sample t-test and oneway Annova were used to assess the association between psychological impact (in terms of depression, anxiety and stress) and maternal age, parity, maternal education, monthly income, gestational age and COVID status.

Table I: Frequency, and severity of depression, anxiety, and stress

\begin{tabular}{|l|l|l|l|}
\hline & $\begin{array}{l}\text { Depression } \\
\text { N (\%) }\end{array}$ & $\begin{array}{l}\text { Anxiety } \\
\text { N (\%) }\end{array}$ & $\begin{array}{l}\text { Stress } \\
\text { N (\%) }\end{array}$ \\
\hline Normal & $227(64.9)$ & $223(63.7)$ & $330(94.3)$ \\
\hline Mild & $96(27.4)$ & $65(18.6)$ & $20(5.7)$ \\
\hline Moderate & $27(7.7)$ & $61(17.4)$ & -- \\
\hline Severe & -- & $01(0.3)$ & -- \\
\hline
\end{tabular}

Total number of women were 350 with mean age of $27.47 \pm 4.72$ years. Their mean gestational age was $26.33 \pm 9.17$ weeks ranging from 6 to 40 weeks.
The mean score of depression, anxiety and stress was $8.00 \pm 2.89, \quad 5.80 \pm 3.10$ and $9.18 \pm 2.80$ respectively. It was observed that depression was present in 123(35.15), anxiety in 127(36.3\%) and stress in $20(5.7 \%)$ study participants that varied from mild to severe as detailed in table $\mathrm{I}$.

There was significant association between level of education and all three domains as detailed in table II. The women who were infected with COVID-19 themselves or any of their family members affected with this infection, showed higher mean score for depression and stress such that $9.33 \pm 3.54$ versus $7.86 \pm 2.78$ and $10.80 \pm 2.60$ versus $9.00 \pm 2.76$. Mean DASS score for stress was higher in young age groups such that $9.12 \pm 3.07$ and $9.57 \pm 2.65$ for age groups of $18-25$ and $26-30$ years respectively versus $8.36 \pm 2.60$ and $8.92 \pm 2.19$ for age groups of 31-35 and 36-40 years respectively. Similarly, stress was higher in women with higher monthly income $(p=0.00)$ as shown in table II. Parity showed association with anxiety $(p=001)$. Mean anxiety was more in house wives $(p=0.00)$ and also depression score was more in house wives $(p=0.00)$ but stress level was more in working women $(p=0.00)$ as detailed in table II.

\begin{tabular}{|c|c|c|c|c|c|c|c|c|}
\hline \multicolumn{9}{|c|}{ Table II: Mean DASS score and associated sociodemographic factors } \\
\hline & & $\mathbf{N}(\%)$ & Depression & P-Value & Anxiety & P-value & Stress & P value \\
\hline \multirow[t]{4}{*}{ Age } & $18-25$ & $124(35.4)$ & $7.79 \pm 2.84$ & \multirow[t]{4}{*}{0.07} & $5.77 \pm 3.04$ & \multirow[t]{4}{*}{0.18} & $9.12 \pm 3.07$ & \multirow[t]{4}{*}{0.04} \\
\hline & $26-30$ & $148(42.3)$ & $8.40 \pm 2.81$ & & $6.07 \pm 3.15$ & & $9.57 \pm 2.65$ & \\
\hline & $31-35$ & $58(16.6)$ & $7.33 \pm 2.76$ & & $5.62 \pm 3.25$ & & $8.36 \pm 2.60$ & \\
\hline & $36-40$ & $20(5.7)$ & $8.30 \pm 3.85$ & & $4.51 \pm 2.37$ & & $8.92 \pm 2.19$ & \\
\hline \multirow[t]{4}{*}{ Parity } & $\begin{array}{l}\text { Primi- } \\
\text { gravida }\end{array}$ & $134(38.3)$ & $7.92 \pm 3.15$ & \multirow[t]{4}{*}{0.10} & $5.87 \pm 3.31$ & \multirow[t]{4}{*}{0.01} & $9.37 \pm 3.14$ & \multirow[t]{4}{*}{0.50} \\
\hline & Multipara & $162(46.3)$ & $8.32 \pm 2.53$ & & $6.14 \pm 2.91$ & & $9.14 \pm 2.53$ & \\
\hline & $\begin{array}{l}\text { Grand } \\
\text { multipara }\end{array}$ & $53(15.1)$ & $7.21 \pm 3.10$ & & $4.56 \pm 2.76$ & & $8.77 \pm 2.68$ & \\
\hline & $\begin{array}{l}\text { Great } \\
\text { grand } \\
\text { multipara }\end{array}$ & $1(0.3)$ & 9.14 & & 7.14 & & 11.28 & \\
\hline
\end{tabular}




\begin{tabular}{|c|c|c|c|c|c|c|c|c|}
\hline \multirow{3}{*}{$\begin{array}{l}\text { Trimester } \\
\text { of } \\
\text { pregnancy }\end{array}$} & $\begin{array}{l}1^{\text {st }} \\
\text { Trimester }\end{array}$ & $41(11.7)$ & $8.11 \pm 3.38$ & \multirow[t]{3}{*}{0.90} & $5.76 \pm 3.24$ & \multirow[t]{3}{*}{0.49} & $9.34 \pm 3.81$ & \multirow[t]{3}{*}{0.89} \\
\hline & $\begin{array}{l}2^{\text {nd }} \\
\text { Trimester }\end{array}$ & $124(35.4)$ & $7.91 \pm 2.96$ & & $5.55 \pm 2.97$ & & $9.11 \pm 2.72$ & \\
\hline & $\begin{array}{l}3^{\text {rd }} \\
\text { Trimester }\end{array}$ & $185(52.9)$ & $8.04 \pm 2.74$ & & $5.98 \pm 3.15$ & & $9.19 \pm 2.60$ & \\
\hline \multirow{7}{*}{ Education } & Illiterate & $21(6.0)$ & $7.02 \pm 2.86$ & \multirow[t]{7}{*}{0.00} & $5.06 \pm 2.51$ & \multirow[t]{7}{*}{0.00} & $8.05 \pm 2.85$ & \multirow[t]{7}{*}{0.00} \\
\hline & Primary & $17(4.9)$ & $6.12 \pm 2.77$ & & $3.79 \pm 3.47$ & & $8.36 \pm 2.94$ & \\
\hline & Middle & $14(4.0)$ & $7.26 \pm 2.84$ & & $4.80 \pm 2.18$ & & $8.03 \pm 2.82$ & \\
\hline & Matric & $97(27.7)$ & $7.90 \pm 3.24$ & & $5.85 \pm 3.10$ & & $8.75 \pm 2.75$ & \\
\hline & Intermediate & $56(16.0)$ & $8.75 \pm 2.42$ & & $6.80 \pm 2.96$ & & $10.23 \pm 2.96$ & \\
\hline & Graduate & $92(26.3)$ & $8.49 \pm 2.82$ & & $6.22 \pm 3.10$ & & $9.18 \pm 2.51$ & \\
\hline & $\begin{array}{l}\text { Masters \& } \\
\text { above }\end{array}$ & $53(15.1)$ & $7.73 \pm 2.53$ & & $5.12 \pm 3.08$ & & $9.84 \pm 2.73$ & \\
\hline \multirow[t]{2}{*}{ Occupation } & Housewives & $332(94.9)$ & $8.05 \pm 2.86$ & \multirow[t]{2}{*}{0.18} & $5.91 \pm 3.07$ & \multirow[t]{2}{*}{0.00} & $9.07 \pm 2.74$ & \multirow[t]{2}{*}{0.00} \\
\hline & $\begin{array}{l}\text { Working } \\
\text { women }\end{array}$ & $18(5.1)$ & $7.12 \pm 3.44$ & & $3.80 \pm 2.94$ & & $11.08 \pm 3.21$ & \\
\hline \multirow{4}{*}{$\begin{array}{l}\text { Monthly } \\
\text { Income }\end{array}$} & 20,000 & $54(15.4)$ & $7.21 \pm 2.68$ & \multirow[t]{4}{*}{0.11} & $5.25 \pm 2.85$ & \multirow[t]{4}{*}{0.30} & $7.59 \pm 2.42$ & \multirow[t]{4}{*}{0.00} \\
\hline & $21-50,000$ & $76(72.0)$ & $8.07 \pm 2.83$ & & $6.00 \pm 2.99$ & & $9.22 \pm 2.73$ & \\
\hline & $\begin{array}{l}51- \\
100,000\end{array}$ & $43(12.3)$ & $8.58 \pm 3.40$ & & $5.34 \pm 2.90$ & & $10.87 \pm 2.59$ & \\
\hline & $>100,000$ & $01(0.3)$ & $8.14 \pm$ & & $5.42 \pm 00$ & & $11.42 \pm 00$ & \\
\hline \multirow{2}{*}{$\begin{array}{l}\text { COVID-19 } \\
\text { infection }\end{array}$} & No & $315(90)$ & $7.86 \pm 2.78$ & \multirow[t]{2}{*}{0.00} & $5.80 \pm 3.08$ & \multirow[t]{2}{*}{0.97} & $9.00 \pm 2.76$ & \multirow[t]{2}{*}{0.00} \\
\hline & Yes & $35(10)$ & $9.33 \pm 3.54$ & & $5.78 \pm 3.25$ & & $10.80 \pm 2.60$ & \\
\hline
\end{tabular}

\section{Discussion}

This cross-sectional study evaluates the psychological impact of Covid-19 pandemic on pregnant women. It reveals that frequency of depression and anxiety is notably high while for stress it is quite low. Similarly, DASS-21 score for depression is in the range of mild to moderate. However, anxiety score varies from mild to very severe. In the current study, level of stress is mild. None of the participants are categorized in score range of very severe. This may be because of lack of awareness about the magnitude of the pandemic situation. Furthermore, all the women who had obstetric and medical risk factors including depression, anxiety and stress were excluded.

In this study it is observed that depression was present in $123(35.1 \%)$, anxiety in $127(36.3 \%)$ and stress in 20(5.7\%) participants with a mean DASSscore of $8.00 \pm 2.89, \quad 5.80 \pm 3.10$ and $9.18 \pm 2.80$ respectively. According to a study in Iran, almost similar prevalence i.e., 32.7\% each for depression and anxiety was seen. However, stress was present in $43.9 \%$ of women in contrast to our study. ${ }^{9}$ The 
similarities may be because of similar sociodemographics. The tool used in both of these studies is DASS-21. In contrast, a study conducted on Japanese women revealed depression in $24(17.7 \%)$, anxiety and stress in $17(12.5 \%)$ each while mean DASS score was $4.8 \pm 5.5,3.0 \pm 4.4$, and $6.2 \pm 7.1$ for depression, anxiety and stress domain respectively. ${ }^{12}$ The prevalence and mean DASS score for depression, anxiety and stress was lower in Japanese women as compared to Pakistani women. This may be due to the difference in ethnicity.

In present study, anxiety found in 127(36.3\%) respondents ranges from mild to severe with $18.6 \%$ mild, $17.4 \%$ moderate and $0.3 \%$ severe. A study conducted on Indian pregnant women revealed that $73.6 \%$ of study population had minimal psychological impact with mean IES-R score of $16.93 \pm 11.23$ and $69.4 \%$ of the study participants had minimal level of anxiety with mean GAD-7 score of $3.09 \pm 3.73$. The frequency of anxiety is almost double in their study but severity of anxiety is minimal as compared to our findings. However, the tool used in their study is different from our study. ${ }^{13}$

Stress was significantly higher in young age groups i.e., $18-30$ years $(p=0.04)$. In contrast, study conducted by Effati Daryani revealed that abnormal depression, anxiety and stress score was associated with age more than 35 years. ${ }^{9}$ This may be because young population has more access to information sources related to the COVID-19 pandemic, more aware of its consequences, myths and facts.

Higher level of education has significant association with all three domains in this study. Similar association was found by Shahid et al. ${ }^{14}$ According to Moyer et al, mothers having university degree had more anxiety as compared to mothers who were less educated. ${ }^{15}$ This may be because of more awareness about the gravity of situation among educated women.

The women who were infected with COVID-19 themselves or any of their family member affected with this infection show significantly higher association with depression $(p=0.00)$ and stress $(p=0.00)$. Stress is found to be more in women with higher monthly income $(p=0.00)$. Negative psychological impact, depression and anxiety prevalence was more in women with higher monthly income as revealed in a study conducted by Shahid et al. ${ }^{14}$ Anxiety and depression is more in house wives $(p=0.00)$ while stress in working women $(p=0.00)$ in our study. In contrast, working women had more negative perception of COVID-19 pandemic according to another study. It may be because of more exposure as compared to housewives. ${ }^{12}$

There is no significant association between depression, anxiety and stress and trimester of pregnancy. Similar results were revealed by studies conducted by Efatti-Daryani et al. ${ }^{9}$ However a study conducted in Italy revealed that women in first trimester had more anxiety and severe psychological impact as compared to women in their second or third trimester of pregnancy. ${ }^{16}$

Number of pregnancies show association with anxiety $(p=001)$ in this study. Higher mean score of DASS is observed in great grand multipara, multipara and primigravida respectively. Study conducted in Iran also disclosed association between anxiety and parity showing gravida three and above having more anxiety as compared to primigravida and gravida two. ${ }^{9}$

Moyer et al reported that higher stress during pregnancy is due to fear of getting infected in 93\%, losing job in $63.7 \%$, loss of child care in $56.3 \%$, food shortage in $59.2 \%$ and conflict between family members in $37.5 \%{ }^{15}$ Fear of getting COVID-19 infection, transmission of infection to newborn, risks to pregnant women, being more vulnerable to infection are the main underlying factors identified by Shahid et al. ${ }^{14}$ Lockdown due to COVID-19 disease have also ill effects on mental health of women because of deprivation of sufficient availability and access to basic needs of life and pregnancy care so it is very important to address the underlying factors leading to negative psychological impact on health of pregnant women. Continuous provision of 
support such as moral, social, family, financial and emotional aspects of their life on one hand and obstetric care on the other hand is crucial. Awareness about the seriousness and sequel of the pandemic must be raised among females so they adopt preventive measures for their well-being and for the safety of their family.

This cross-sectional study has evaluated a sufficient sample size for mental health of pregnant women in terms of depression, anxiety and stress however it is a single centered study. Results of single centered study cannot be generalized. Further research is needed to identify the underlying reasons of this psychological impact.

\section{Conclusion}

Frequency of depression and anxiety was notably high while for stress it was quite low. Severity of depression varied from mild to moderate, anxiety from mild to severe. However, severity of stress was mild. DASS-21 score was significantly associated with educational level in all three domains such that depression, anxiety and stress. The women who were infected with COVID-19 themselves or any of their family members affected with it showed positive association for depression and stress.

\section{Recommendation}

Routine screening for mental wellbeing should be started in obstetrical settings. This will be helpful to address any deleterious effects on mental health and timely intervention if required for healthy fetomaternal outcome.

\section{References}

1. Government of Pakistan. Coronavirus in Pakistan. http://covid. gov.pk/. Accessed March 27, 2020.

2. World Health Organization. Pakistan: COVID-19Situation update as of 7 April 2020. Updates: Ministry of National Health Services Regulations and Coordination Dashboard; 2020.

3. Abid K, Bari YA, Younas M, Tahir Javaid S, Imran A. Covid19-Progress of COVID-19 Epidemic in Pakistan.
Asia-Pac J Public Health. 2020; 32(4):154-6. Doi: $10.1177 / 1010539520927259$

4. Hasanjanzadeh P, Faramarzi M. Relationship between maternal general and specific-pregnancy stress, anxiety, and depression symptoms and pregnancy outcome. JCDR. 2017;11(4):VC04. Doi: 10.7860/JCDR/2017/24352.9616

5. Ahmed B, Enam SF, Iqbal Z, Murtaza G, Bashir S. Depression and anxiety: a snapshot of the situation in Pakistan. Int J Neurosci and Behavi Sci. 2016;4(2):32. Doi: 10.13189/ijnbs.2016.040202

6. Zahidie A, Jamali T. An Oerview of the Predictors of Depression among Adult Pakistani Women. J Coll Physicians Surg Pak.2013; 23(8):574-80. PMID: 23930875

7. Fan S, Guan J, Cao L, Wang M, Zhao H, Chen L, et al. psychological effects caused by COVID-19 pandemic on pregnant women: A systemic review with metaanalysis. Asian J. Psychiatr.2020:102533. Doi: 10.1016/j.ajp.2020.102533

8. Ceulemans M, Hompes T, Equlon V. Mental health status of pregnant and breastfeeding women during the COVID-19 pandemic: A call for action. Int. J. Gynecol Obstet.2020; 151(1):146-7. Doi: 10.1002/ijgo.13295

9. Effati-Daryani F, Zarei S, Mohammad A, Hemmati E, Yngyknd SG, Mirghafourvand M. Depression, stress, anxiety and their predictors in Iranian pregnant women during the outbreak of COVID-19.BMC psychology.2020;8(1):1-10. Doi: 10.1186/s40359020-00464-8

10. "Depression Anxiety Stress Scale (DASS)". Psychology Foundation of Australia. $<$ http://www2.psy.unsw.edu.au/dass/>

11. Aslam N, Tariq N. Trauma Depression Anxiety and Stress among individuals living in earth quake affected and unaffected areas. Pak J Psychol Res. 2010.25(2):131-48.

12. Suda T, Miura $Y$, Katayama $M$, Senba $H$, Takahata $M$, Nakano S. Worries and concerns about COVID-19 lockdown aggravate stress reactions among pregnant women. Research Square.2020. Doi: 10.21203.rs.3.rs-45832/v1.

13. Jelly P, Chadha L, Kaur N, Sharma S, Sharma R, Stephen S, et al. Impact of COVID-19 Pandemic on the Psychological Status of Pregnant Women. Cureus. 2021; 13(1).: e12875. Doi: 10.7759/cureus.12875.

14. Shahid A, Javed A, Rehman S, Tariq R, Ikram M, Suhail M. Evaluation of psychological impact, depression and anxiety among pregnant women during the COVID-19 pandemic in Lahore Pakistan. Int J Gynae\& Obs. 2020; 151(3):462-5. Doi: 10.1002/ijgo.13398 
15. Moyer CA, Compton SD, Kaselitz E, Muzik M. Pregnancy-related anxiety during COVID-19: a nationwide survey of 2740 pregnant women. Arch Womens Ment Health. 2020;23(6):757-65. Doi: 10.1007/s00737-020-01073-5
16. Saccone G, Florio A, Aiello F, Venturella R, De Angelis MC, Locci $M$, Bifulco $G$, Zullo $F$, Sardo AD. Psychological impact of coronavirus disease 2019 in pregnant women. AJOG. 2020;223(2):293-5. Doi: 10.1016/j.ajog.2020.05.003 